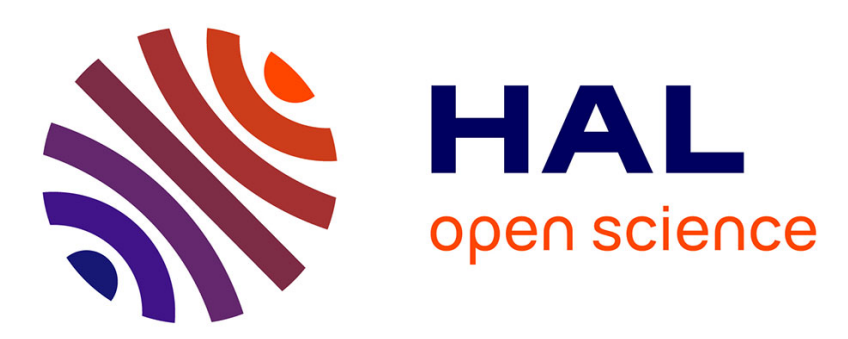

\title{
Mathematisation of the Science of Motion and the Birth of Analytical Mechanics: A Historiographical Note \\ Marco Panza
}

\section{To cite this version:}

Marco Panza. Mathematisation of the Science of Motion and the Birth of Analytical Mechanics : A Historiographical Note. P. Cerrai, P. Freguglia, C. Pellegrini,. The Application of Mathematics to the Sciences of Nature. Critical moments and Aspects, Kluwer A. P., Plenum P., New York, pp.253-271, 2002. halshs-00116699

\section{HAL Id: halshs-00116699 \\ https://shs.hal.science/halshs-00116699}

Submitted on 27 Nov 2006

HAL is a multi-disciplinary open access archive for the deposit and dissemination of scientific research documents, whether they are published or not. The documents may come from teaching and research institutions in France or abroad, or from public or private research centers.
L'archive ouverte pluridisciplinaire HAL, est destinée au dépôt et à la diffusion de documents scientifiques de niveau recherche, publiés ou non, émanant des établissements d'enseignement et de recherche français ou étrangers, des laboratoires publics ou privés. 


\title{
Mathematisation of the Science of Motion and the Birth of Analytical Mechanics. A Historiographical Note
}

\author{
Marco Panza* \\ CNRS, REHSEIS, UMR 7597 (CNRS and Univ. of Paris 7)
}

Usually, one speaks of mathematisation of a natural or social science to mean that mathematics comes to be a tool of such a science: the language of mathematics is used to formulate its results, and/or some mathematical techniques are employed to obtain these results.

It seems to me that the notion of mathematisation is misleading when used in this sense, however. Instead, we should distinguish what I would like to call "mathematisation" from something quite different I would call "application of mathematics".

We should speak of application of mathematics to a natural or social science when a natural phenomenon that such a science is studying is described or explained using mathematics, or when a problem this science aims to solve is answered by means of mathematical techniques. By contrast, we should speak of mathematisation only when the object of this science becomes a mathematical object, i.e. mathematics provides a model or a scheme of a natural or social phenomenon and this model or scheme becomes the real object of studying. I shall illustrate this distinction by means of the example of the science of motion from Aristotle to the middle of 18th century. The same example will also be used to illustrate another topic, namely when analytical mechanics was born.

\footnotetext{
* The present paper has been completed during a visiting scholarship at the Faculty of Sciences (dpt. of Mathematics) of the University of Mexico-City (UNAM). I thank it for its logistic and financial support. I thank also Pierre Souffrin for useful discussions concerning a part of my paper.
} 
Concerning my first topic, the standard view maintains that the mathematisation of the science of motion begins within 17th century, specially thank to Galileo. Moreover, it maintains that the mathematisation of the science of motion is a distinctive character of the "scientific revolution". But, I do not think that something as a "scientific revolution" occurred in 17 th century (or in some other date in the history of science). I shall not discuss this point here however. I will confine myself to argue, according to my previous distinction, that when application of mathematics to the science of motion is a usual practice within Aristotelian physics, no mathematisation of this science occurs before Newton. From such point of view, Galileo's theories of motion share with Scholastic theories an essential aspect: they do not deal with a mathematical object, but they merely use a mathematical theory (that is actually a suitable version of classical theory of proportion) to deal with some natural phenomenon.

Concerning my second topic, there is no standard view. That analytical mechanics was born in 18th century is a well-grounded historiographical judgement. When it is used in historiographical contexts, the term "analytical mechanics" is quite imprecise, however. This made the previous judgement open to different interpretations, each of them ascribing to this term a different meaning. I shall consider two examples of such different conceptions that seem to me to be opposite end extreme.

\section{Two opposite conceptions about the birth of analytical mechanics}

In his many and fundamental essays on the history of mechanics, Clifford Truesdell seems to use the term "analytical mechanics" in a very strict sense. According to him this term has to be used, in historiografical contexts as well in scientific ones, to designate a part of mechanics and specifically of rational mechanics. The following quotation is typical of this attitude:

Mechanics appears [in Lagrange's Méchanique analitique ${ }^{1}$ ] as a physically closed subject, a branch of the theory of differential equations.

[...] As its title implies, the Méchanique Analitique is not a treatise on rational mechanics, but rather a monograph on one method of deriving differential equations of motions, mainly in the special branch now called, after it, analytical mechanics. ${ }^{2}$

\footnotetext{
${ }^{1}$ Cf. Lagrange (1788).
} 
A similar judgement is also advanced by Truesdell in the preface of his First $C^{`}$ urse in Rati nal C`ntinuum Mechanics:

[...] that book [Lagrange's Méchanique analitique] covers only certain aspects o the rational mechanics created by Lagrange's great predecessors [...].

In 1788 [the date of publication of Lagrange's Méchanique analitique] the mechanics of deformable bodies, which is inherently not only subtler, more beautiful, and grander but also far closer to nature than is the rather arid special case called "analytical mechanics", had been explored only in terms of isolated examples, brilliant but untypical. ${ }^{3}$

Thus, according to Truesdell's conception, the term "analytical mechanics" has to be used in historiographical context, in a sense that is very close to the sense it takes in the presentday treatises of classical mechanics, where it refers to that part of mechanics that treats of the equations of motion for dynamic systems, and particularly of the equations connected to the Lagrange's ones.

Of course, in Truesdell's interpretation the adjective "analytical" qualifies the term "mechanics" by limiting its scope. This limitation entails a number of different aspects. The first aspect is quite obvious, being connected with the fact that, by speaking of analytical mechanics, we are implicitly speaking of classical (rather than relativistic or quantum) mechanics. By contrast, the second aspect is only apparently obvious. Though it is connected with the plain fact that, by speaking of analytical mechanics, we are implicitly speaking of mathematical mechanics, it is not so obvious because of the way in which Truesdell means this fact. He seems to think first that mechanics' being mathematical is the same that its being rational. Then he assumes that, since it is mathematical, rational mechanics is, as such, a part of mathematics ${ }^{4}$. Finally he maintains that rational mechanics "is that part of mathematics that provides and develops logical models for the enforced changes of positions and shape which we see everyday things suffer"5. In the first of these attitudes, Truesdell follows Newton who in the preface to the Principia (that is for Truesdell

\footnotetext{
${ }^{2}$ Cf. Truesdell (1968), p. 134 ("A Program toward Rediscovering the Rational Mechanics of the Age of Reason“, first publication in 1960, Archive f r Hist` ry `f Exact Sciences, 1, 1960-1962, 3-36).

3 Cf. Truesdell (1977), vol. I, p. XI.

${ }^{4}$ Cf. for example Truesdell (1968), p. 335 ("Recent Advances in Rational Mechanics", first published, in a different version in Science, 127, 1958, pp. 729-739).

${ }^{5}$ Cf. Truesdell (1977), vol. I, p. 4. As Truesdell explicitly remarks the term "things" refers here to natural things (as animals, plants, seas, minerals, planets, etc.) and man's artifices.
} 
the first treatise of rational mechanics ${ }^{6}$ ) maintained that mechanics is either rational or practical and, when it is rational, it "accurate procedit" and thus "ad geometriam referatur" The third aspect is only apparently obvious too. For it is concerned with the fact that mathematics which enters analytical mechanics is a particular one: it is just analytical mathematics. The difficulty is here concerned with the different sense of this last term: "analytic mathematics". I confine myself here to observe that for Truesdell this means that mathematics is here merely a tool to provide a formalistic exposition of mechanics, where this was not the case, for example, for Jean Bernoulli or Euler which used mathematics to make clear the fundamental concept of rational mechanics ${ }^{8}$. Finally, the fourth aspect is in no sense obvious at all. It comes from Truesdell's attitude to transpose on historical contexts the present-day practice to consider analytical mechanics as concerned only with a certain sort of mechanical problems and a certain type of formalism. In the already quoted preface of the Principia, Newton says that "Mechanica rati nalis erit Scentia Motuum qui ex viribus quibscunque resultant, et virium quæ ad motus quoscunque requiruntur, accurate proposita ac demonstrata" 9 . Truesdell seems to assume that rational mechanics as such understands this definition in a large sense, while analytical mechanics understand it in such a limiting sense to constraint itself to the consideration of the motion (and equilibrium) of discrete systems of bodies (also considered under certain restrictive conditions).

Starting from a similar conception, Truesdell has to assume that analytical mechanics is essentially the result of Lagrange's formalistic conception of mathematics, even though other works, as Euler's Mechanica ${ }^{10}$ for example ${ }^{11}$, are part of its early history.

The second example refers to a more widespread attitude among historians of mechanics and mathematics. This attitude has been very well exposed by Michel Blay in his book

\footnotetext{
${ }^{6}$ Cf. Truesdell (1968), p. 335 ("Recent Advances [...]”, ‘p. cit.).

${ }^{7}$ Cf. Newton (1687), Prafati ad lect rem, first page [not numerated].

8 Cf. Truesdell (1968), pp. 133-134 (“A Program [...]”, `p. cit.).

${ }^{9}$ Cf. Newton (1687), Profati ad lect rem, first page [not numerated].

10 Cf. Euler (1736).

${ }^{11}$ Cf. Truesdell (1968), p. 106 (“A Program [...]”, ’p. cit.).
} 
concerned with the Naissance de la mécanique analytique ${ }^{12}$. Blay assumes that the term "analytical mechanics" in the title of his book refers to an analytical (rather that a geometrical) way to do mechanics. I quote the Avant-pr ` $p$ `s of Blay’s book:

$[\ldots]$ ce livre $[\ldots]$ est construit autour de deux questions précises:

- Comment la conceptualisation differentielle de la science du mouvement a-t-elle été obtenue?

- Comment cette concetualisation différentielle a-t-elle pu favoriser la réorganisation et le développement de la science de mouvement?

Partant de ces deux questions, nous voudrions déterminer aussi exactement que possible par quelles démarches et au moyen de quels concepts une science analytique du mouvement a réussi à se constituer. ${ }^{13}$

Thus, for Blay, as well as for Truesdell, the adjective "analytical" qualifies the term "mechanics" by limiting its scope, but the only aspect of such a limitation, on which Blay seems to agree completely with Truesdell, is the first of the previous ones: by speaking of analytical mechanics, we speak of classical mechanics. Of course, there is also a sense in which Blay agrees with Truesdell on the second and third aspect, but it seems to me that this is just the sense that makes these aspects obvious: analytical mechanics is a mathematical theory and it is concerned with a particular sort of mathematics. Starting from his premises, Blay obviously maintains that analytical mechanics origins when Newtonian mechanics is translated from its original geometrical style in an analytical (that is a differential) language. According to Blay, this is initially done by Pierre Varignon who devoted to such an aim a number of papers between 1698 and $1711^{14}$. To discuss these papers is the principal matter of Blay's book.

In his short article on classical mechanics in Grattan-Guinness' C’mpani n Encycl paedia, Craig Fraser accepts a perspective very similar to Blay's ${ }^{15}$. Here is what he writes under the title "Analytical Mechanics":

The eighteen-century progress of theoretical mechanics occurred almost entirely on the Continent, using the mathematics of the Leibnitian calculus. The Principia became historically influential once its theory had been absorbed by researches working in the scientific academies of Paris, Berlin and St Petesburg. The French priest Pierre Varignon wrote a series of memoirs beginning in 1700 on orbital dynamics that employed Leibnitian analytical methods. He gave an elegant demonstration of Principia,

12 Cf Blay (1992).

13 Cf. ibid., p. 8.

14 Cf. Blay (1992), pp. 153-221 and 277-321, where a complete bibliography of Varignon's papers on this subjects is given, and Bertoloni-Meli (1993), pp. 201-205.

15 Cf. Fraser (1994), particularly pp. 973-975. 
Book I, Proposition 11 that replaced Newton's involved geometric reasoning by a simple algorithmic procedure. Varignon contemporaries John I Bernoulli and Jakob Hermann also contributed to his subject, providing a uniform mathematical treatment of the so-called 'inverse problem' in which it was required to determine the orbit from a knowledge of the force law. ${ }^{16}$

Fraser insists, however, on the essential role, in the development of the analytical mechanics, of Euler's differential formulation of the second Law of Newton, occurred only in $1750^{17}$.

I do not want to deny the legitimacy of the two previous interpretations of the term "analytical mechanics" in historical contexts. On the one hand, their difference can be finally reduced to a merely terminological one and it is also possible that the distinctions introduced by Truesdell are accepted by someone that decides to use the term "analytical mechanics" in historical contexts as Blay and Fraser do. On the other hand, it is clear that neither Truesdell, nor anyone else can deny the existence of a relevant difference between the geometrical style of Newton's Principia and the analytical style of the most part of treatises and memoirs devoted to mechanical subjects in the 18th century. Since Blay and Fraser use the term "analytical mechanics" just to refer to such an important difference, that I am obviously far to deny, it is clear that I can not disagree on any important point with them. Besides, even though I can follow Truesdell neither in his idiosyncratic insistence in diminishing the role and importance of Lagrange's contributions to mechanics and in reducing them to a mere formalistic compilation, nor in his implicit elimination of Aristotelian tradition from the history of mechanics, I think his distinctions are correct and I agree with him in stressing that 18th century mechanics was not only (and perhaps not mainly) a theory of motion and equilibrium for discrete systems of bodies.

Thus, the only incompatibility between the thesis I will defend here and the previous ones is terminological. But, since the term which is concerned-that is just the adjective "analytical"-is a crucial term in a very large number of scientific texts in the 18th century,

\footnotetext{
${ }^{16}$ Cf. ibid., p. 974.

17 Cf. Euler (1750). Note that in this paper, Euler presents the Nawton's law (in his new formulation) as a "new principle of mechanics" that he pretends to have discovered. Lots of papers have been written on the subject of Newton's second Law where distinct interpretation of it and of its role and meaning in the Principia are discussed. Among the more recent ones, cf. Verlet (1996) where a large bibliography is given.
} 
this terminological incompatibility has a more fundamental meaning and is strictly connected with my first distinction between the application of mathematics to a certain science and the mathematisation of this science. I think that when the adjective "analytical" is used in 18th century to refer to mechanics, it takes a meaning which is both narrower than that Blay and Fraser ascribe to it and larger than that Truesdell ascribes to it. My only aim is to suggest a possible reconstruction of this meaning.

As I have already anticipated, I shall consider here only one example, that is that of the science of motion, and even more particularly, the theories of motion of one or more (indeformable and distinct) bodies. Of course, mechanics is more than that. Nevertheless, I maintain that this example is historically relevant as such.

Before presenting my point (and justifying my historical judgements) let me sketch what I mean as the main lines of the development of the theory of motion from Aristotle to Newton. This shall allow me to illustrate partially my first distinction.

\section{Classical frameworks in the science of motion from Aristotle to Newton}

Even though Aristotle provides, in the third book of Physics, a logical definition of it as

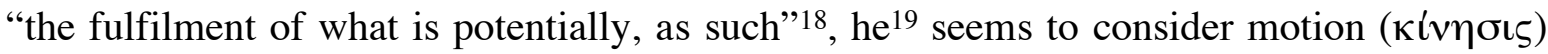
as a primitive phenomenon. The definition need not introduce or fix the notion of motion, but provides only a logical analysis of it, in terms of the fundamental notions of the science of being, or metaphysics. We could even claim that with such a definition Aristotle legitimates the notion of potentiality, "en lui faisant représenter conceptuellement une réalité physique évidente" 20 . Aristotelian science of motion is thus the science of such a reality and not a science of an abstract object defined in terms of the primitive notions of fulfilment and potentiality. Moreover, Aristotle appeals to motion, as a real phenomenon, in order to characterise both nature and the science of nature, since, according to him, nature is "a principle or cause of being moved" 21 , and the science of nature is essentially the science of motion. The reality of motion is a composite reality, however, since there are different

\footnotetext{
${ }^{18}$ Cf. Aristotle, Physic, 201a 10-11.

${ }^{19}$ I have discussed Aristotelian conception of motion in Panza (1992b).

${ }^{20}$ Cf. Carteron (1923), p. 211.

${ }^{21}$ Cf. Aristotle, Physics, 192b 21.
} 
sorts of motion, according to the different modalities of fulfilment or potentiality. Such a difference is also a primitive reality and it is as such perfectly evident to us. Namely, we are able to distinguish displacement $(\varphi \circ \rho \alpha)$ - that is the fulfilment of the potentiality of taking certain different positions or occupying certain places - from other kinds of motion.

By contrast, according to Aristotle, time is not a primitive or external reality, but only a phenomenological form of our perception of motion, or an abstract representation of it. Logically, it is the "number of motion in respect of 'before' and 'after'" 22 , where the term "number" refers to what is numbered, rather than to what we use to number. However, the time, understood as the number of a certain motion, can be used to measure other motions. Namely, the number of the first (eternal, necessary and continuous) motion - that is the circular displacement of the first heaven - can be used to measure particular motions.

These are nothing but local and accidental consequences (or even local expressions, or accidental particularisations) of the first motion due to particular causes. As such, they are not only characterised by their respective measures, according to the time of the first motion, but also by the particularity both of the potentiality of which they are the fulfilment and of their subject. These positions change from a point to another point by following a continuous path, while time ${ }^{23}$ (continuously) evolves from an instant to another instant ${ }^{24}$. Thus, by abstracting from the particular bodies which are moving and from the causes of their motions, different particular displacements can be compared-as quantities are compared (that is according to an order relation, including the possibility of equality between distinct objects) - by comparing their paths and the respective times. As this is a double comparison and paths are not always comparable as such, Aristotle can not get in

\footnotetext{
${ }^{22}$ Cf. ibid., $219 \mathrm{~b} 2$.
}

${ }^{23}$ In what follows, I shall use the term "time" to refer both to the time of the first motion, that is the time as such, and to a fragment of the time of the first motion, that is a temporal interval. The context will make clear what of these meanings is intended.

${ }^{24}$ Even though such a description of a particular displacement in term of a moving body, a path and a certain time seems to be accepted by Aristotle as perfectly legitimate, it is far to be unproblematic in Aristotelian framework. As a matter of fact, the exigency to make it clearer is one of the main motivations for scholastic discussions about motion. I dealt with an example of these discussions in my (1994), where a large bibliography of secondary literature is also provided 
such a way a total order of displacements and he is only able to compare certain particular displacements to certain other ones.

In fact, though Aristotle speaks about speed, when two particular displacements are compared in such a way, we have not to imagine that he compares the displacements by comparing their respective speeds. Even though any particular displacement has for Aristotle a certain speed, he never says exactly what speed is, and how it is measured in terms of the path of this displacement and of the time taken to cover it. Aristotle could not have been able to define speed as the ratio of space and time. This does not only depend on its general conception of nature and of its first principles, it is also connected to the absence in Greek mathematics of something similar to our conception of ratio between two quantities, particularly if two non-homogeneous quantities-as a path and a time-are considered. As long as it can not be a ratio (or any sort of entity defined in terms of space and time), speed is, according to Aristotle, a specific and primitive property of particular displacements, that is a quality of real phenomena. Of course, this property changes when the covered path and the corresponding time change and vice versa, but it is not determined as such when this path and this time are determined: it is not reducible to them.

In short, for Aristotle motion is a natural primitive phenomenon that can be characterised in general in term of the fundamental metaphysical categories of fulfilment and potentiality and described in its particular manifestation by specifying the particular body which is moving, the causes of its motion, the path this body covers, the time it takes to do it, and the speed with which it does it. From such a point of view no mathematisation of the science of motion is of course possible. No obstacle forbids to apply mathematics to the study of motion, however. Though Aristotle did not write, as long we know, any mathematical treatise on motion, he referred, in a number of occasions, to some mathematical notion in order to speak about motion. In particular, he did it when he considered the relations different displacements have with each other.

If two displacements take the same time (or equal times) and the paths are comparablei.e. we can speak about distances, rather than paths in general - the order of distances is also the order of speeds. If the paths of two displacements - or the distances covered by themare equal, the order of times is opposite to the order of speeds. If neither the paths covered by two displacements, nor the corresponding times are equal, these displacements can not be ordered in the Aristotelian framework. Nevertheless, if their paths are comparable, such a 
framework is at least compatible with the possibility of stating certain relations between two hypothetical distinct motions.

In the chapter VII.5 of Physics, Aristotle states quite clearly four rules or theorems about motion and the possible relations of two hypothetical distinct motions ${ }^{25}$. He provides, of course, quite a discursive formulation of these rules, but their content can be formulated in a more formal language. In order to do it, I suppose that:

$-s(x, y, z)$ is the space covered by the mobile $x$ upon which the force $y$ is applied during the time $z$;

$-t(x, y, z)$ is the time taken by the mobile $x$ upon which the force $y$ is applied to cover the space $z$.

Then, the rules of Aristotle consist of the previous implications (where $n$ is any positive integer; I put " $n$ " where, to be faithful to Aristotle's text, I should put " 2 ", since it is clear that Aristotle is here making an exempla of any integer multiple or sub-multiple):

R.1 if $s(n M, F, T)=S$ then $s(M, F, T)=n S$;

R.2 if $t(n M, F, S)=n T$ then $t(M, F, S)=T$;

R.3 if $t(M, F, n S)=n T$ then $t(M, F, S)=T$;

R.4 if $t(n M, n F, S)=T$ then $t(M, F, S)=T$

Aristotle claims that it is so because "in this way, the proportion is preserved" 26 . This is not really a prove, however, and, really, it would be difficult to understand how he could really prove his rules, without starting from any definition or postulate fixing the relations between mobiles, distances covered, forces applied upon a mobile, and time during which this is applied. Probably, he thought that these rules were evident enough to provide a description of the relations that would take place between two real distinct motions if they satisfied the conditions indicated in these rules. Thus, he does not define in general the notions he is employing in stating his rules, just because he thinks that these notions simply refer, in general, to empirical entities we can distinguish in reality when considering a particular motion. Nevertheless, it is easy to imagine something like some general laws that

\footnotetext{
25 Cf. Aristotle, Physics, 249b, 30 - 250a, 7.

26 Cf. ibid., 250a 4.
} 
can be formulated in the framework of the classical theory of proportion, starting from which the rules of Aristotle, or other similar rules, can be proved. In Aristotle's rules, speed is not mentioned. It could occur in these general laws, however, and be used in the proof of Aristotle's rules as an intermediate term. The following are two groups of laws fixing respectively the relations between space, time and speed and between force, resistance and speed. I use the term "resistance" to refer, in the Aristotelian spirit, to something that opposes the motion: force brings about motion and resistance opposes the latter. If $S_{i}, T_{i}, V_{i}$, $F_{i}$, and $R_{i}(i=1,2)$ are respectively the space (or distance) covered by two distinct motions, the times these motions take, their speeds, the forces that bring about them, and the resistances that oppose them, while $K, L, H$ are three magnitudes taken in order to satisfy the antecedents of the implications, then these laws are:

L.I.1 if $S_{1}: S_{2}=K: L$ and $T_{2}: T_{1}=L: H$, then $V_{1}: V_{2}=K: H$

L.I.2 if $V_{1}: V_{2}=K: H$ and $S_{1}: S_{2}=K: L$, then $T_{2}: T_{1}=L: H$

L.I.3 if $V_{1}: V_{2}=K: H$ and $T_{2}: T_{1}=L: H$, then $S_{1}: S_{2}=K: L$

L.II.1 if $F_{1}: F_{2}=K: L$ and $R_{2}: R_{1}=L: H$, then $V_{1}: V_{2}=K: H$

L.II.2 if $V_{1}: V_{2}=K: H$ and $F_{1}: F_{2}=K: L$, then $R_{2}: R_{1}=L: H$

L.II.3 if $V_{1}: V_{2}=K: H$ and $R_{2}: R_{1}=L: H$, then $F_{1}: F_{2}=K: L$

If we the mobile occurring in the Aristotle's laws is intended as a resistance, the proof of his rules starting from these laws is easy. I will just consider R.1. If one put $R_{1}=n M$, $R_{2}=M$, and $F_{1}=F_{2}=F$, then the two premises of L.II.1 become respectively $F: F=1: 1$ and $M: n M=1: n$; thus, according to this law we have: $V_{1}: V_{2}=1: n$. If one pose then $T_{1}=T_{2}=T$, the two premises of L.I.3 become respectively $V_{1}: V_{2}=1: n$ and $T: T=n: n$, thus, according to this law we have: $S_{1}: S_{2}=1: n$. From this it follows that if $S_{1}=S$, then $S_{2}=n S$, that is exactly what R.1 states. The proofs of the other rules are similar.

I do not want to argue either that Aristotle actually asserted the laws L.I.1-3 and L.II.1-3, or that he referred to them implicitly. I simply argue that these rules formulate in a mathematical language, which was perfectly at disposal of Aristotle and the scholastics, some relations between some aspects or properties of actual motions that seem to be implicitly accepted by the latter. The laws of the first group compare two distinct motions, whatever they are, by stating some relations between the mutual ratios of the distance they 
cover, the time they take and the speed the have. In these way they fix the relations between the distance covered by any motion, the time it takes and its speed. By using a typical language of theory of proportions, the first law of this group states that the speeds of two motions are between them in the composed ratio ${ }^{27}$ of the distances they cover and the times they take to do it. The other two laws state the converse of the same. The laws of the second group compare two distinct motions, whatever they are, by stating some relations between the mutual ratios of the forces that bring about them, the resistances that oppose to them, and their speeds. In these way they fix the relations between the force that brings about any motion, the resistance that opposes it and its speed. By using the language of theory of proportions again, the first law of this group states that the speeds of two motions are between them in the composed ratio of the forces that bring about them and the ratio of the resistances that oppose them ${ }^{28}$. In this case as well, the two other laws state the converse of the same.

These are two different ways to compare motions, the first one according to their effects, the second one according to their causes. Thus, the previous laws and the deduction from them of the rules of Aristotle prove that the Aristotelian conception of motion, both of its effects and of its causes, is compatible with an application of mathematics to the science of motion, even if it is far away from any sort of mathematisation.

These two distinct ways of comparing and characterising displacements, either according to their effects or according to their causes, are both part of the Aristotelian science of displacements. Though the second one is typical of the official Aristotelism, at least at 17th century - so much that we could define Aristotelian theory of displacements, as a "physical theory of displacements and their causes" 29 - the first one provides the basis for the main result (from a modern point of view) of this science, that is the distinction between uniform, uniformly difform and difformly difform displacements, introduced in the 14th century by

\footnotetext{
27 Note that the term "ratio" does nor refer here to a specified object, as it does today; it is only a technical term occurring in the description of a certain system of proportions.

28 Cf. Giusti (1990), p. XIII.

${ }^{29}$ Cf. ibid., p. XXIII.
} 
Oresme and the Mertonians ${ }^{30}$. Such a distinction does not need any reference to the notions of speed and acceleration as variable ratios. Speed is nothing but a quality, whereas acceleration, or better difformity, is nothing but the phenomenon of variation of the intensity of speed. The previous distinction is thus a particular application of a more general distinction, concerning the modalities of variation of the intensity of a quality. A certain body moving according to a certain displacement is thus a particular subject with a certain quality, that is just speed. The intensity of such a quality can change in different ways. In particular, it can change with time and hence be taken as an instantaneous quality. This change can be either uniform or difform; in the first case the displacement is also uniform, while in the second case it is difform. This is a very natural distinction, but it can work only if we know, by an independent source, what the quality of speed is or, at least, how it can be measured. The basic idea both of the Mertonians and Oresme is that of measuring speeds by using the rectilinear spaces covered in a certain time by the moving bodies which are affected by these speeds, taken as constant with respect to this time. Thus ${ }^{31}$, the displacement of a certain body is uniform, if the spaces covered by this body in equal times are always equal, otherwise it is difform. Moreover, if it is difform, it is uniformly difform, if "in quacunque equali parte temporis, equalem acquirit latitudinem velocitatis".

The latter definition is, as such, quite obscure, since spaces are not mentioned. However, if we represent time by using a certain axis and different speeds at the extremes of equal times by means of equidistant perpendicular segments to such an axis, such a definition is perfectly sufficient for concluding that when the displacement is uniformly difform the extremities of these segments fall all on a straight line oblique with respect to the axis, while they fall on a straight line parallel to the axis, if the displacement is uniform. This is the basis of Heytesbury's and Oresme's ${ }^{32}$ diagrammatic representation of uniform and uniformly difform displacements and of the consequent proof of the "theorem of Merton college" which appeals to the comparison of these diagrams. This theorem states that the distances covered by a uniformly difform displacement at any given time is the same as that which is covered by a uniform rectilinear displacement, with a constant speed equal to the

\footnotetext{
${ }^{30} \mathrm{Cf}$. for a deep survey Clagett (1959).

${ }^{31}$ Cf. ibid, pp. 238 e 241-42 [doc. 4.4. ("William Heytesbury, Rules f $r S^{`}$ lving S` phisms"), 14-17 e 89-97].

32 Documents are in Glagett (1959) and (1968).
} 
speed of the uniformly difform motion in the middle of this time. Though it explicitly deals with speed as an instantaneous (or punctual) quality, the proof of this theorem is not founded on any explicit definition, either of speed in general, or of instantaneous (or punctual) speed. It simply works because of a diagrammatic formalism associated to the metaphysical idea of speed (or quality, in general). This formalism is far for providing a mathematical object modelling the real phenomenon of motion. It is only a convenient way to speak about it and represent certain of its properties. Once again it makes possible a convenient application of mathematics to the science of motion, but is far from being the result of a process of mathematisation.

Different interpretations are possible of both Heytesbury's and Oresme's proof ${ }^{33}$. All of them agree on an essential point, however: these proofs have nothing to do with the classical paradigm of the theory of proportions. Under certain possible interpretations, they even break the most fundamental clause of this theory-that is, homogeneity-by considering a certain surface both as a representation of a linear distance and as the result of an infinite sum of segments representing instantaneous speeds. By contrast, for Galileo (who nevertheless proves twice the theorem of Merton College, by two distinct arguments, both analogous, even if not equivalent, to those of Heytesbury and Oresme ${ }^{34}$ ), as long as the science of motion is a mathematical science, it is founded on the theory of proportion. At most, this theory should be reformed, for the new aims of the science of motion ${ }^{35}$, but it can not be substituted with alternative formalisms.

According to Galileo ${ }^{36}$, there is no unitary science of Aristotelian motion. Even though he still speaks of "local motion" (that is, displacement) to specify the object of his research, for him the science of motion is nothing but the mathematical science of displacements, since motions are nothing but displacements. Moreover, this science does not deal with the causes of motions - it is not a form of dynamics (or a theory of gravity and lightness) - but it deals, like in Oresme's and the Mertonians' approach, with motions as long as they are

\footnotetext{
33 I have discussed Heytesbuury's proof in my (1994).

34 Cf. Galilei (1632), 2th Gi rnata (Ed. Nat., pp. 254-256) and (1636), 3th Gi rnata (Ed. Nat., pp. 208-209).

35 Cf. Giusti (1993).

36 The l'cus classicus for Galileo's science of motion is obviously Galilei (1638), 3th and 4th Gi rnata.
} 
characterised in terms of spaces that are covered and times that are spent for that - it is properly a kinematics (a theory of space and time) ${ }^{37}$. Nevertheless, even though this science has to be, according to Galileo, a mathematical science, it does not introduce its objects as mathematical ones. Rather it is founded on a mathematical characterisation of physical phenomena. Once again, Galileian science of motion results from an application of mathematics to the study of motion and not from a process of mathematisation. Galileo does not study, for example, uniformly accelerated motion, rather he studies the "natural motion" of a falling body. He recognises - by experimental and rational arguments - that this motion is such that speed uniformly changes in it, characterises it as a motion which satisfies a certain mathematical property in the context of the theory of proportions, and then looks for a deduction of its laws starting from such a mathematical characterisation. Both the first and the second stage of this research were far from being easy. As a young man, Galileo believed that the natural motion of a falling body was essentially uniform, afterwards he was quite sure that instantaneous speed was proportional to the covered space, rather than to the elapsed time ${ }^{38}$.

Still, even when Galileo recognised that the natural motion of a falling body is "uniformly accelerated", he did not characterise it as a motion whose acceleration is constant, since acceleration was not a quantity for him, but just a variation of speed (or a cause of such a variation). Moreover, he did not reduce speed to space and time, by means of an explicit mathematical definition. As long as it is a quantity, speed is as such, independent from space and time. As long as it is possible to provide correlative definitions of these three quantities, these definitions are just metaphysical characterisations and do not provide any sort of mathematical reduction. The problem of fixing the mathematical relations between these quantities is thus independent from the problem of definying or characterising them. This is a very natural situation in the context of the theory of proportion, where the condition of homogeneity prevents two non homogeneous quantities from operating with each other ${ }^{39}$.

\footnotetext{
${ }^{37}$ Cf. Giusti (1981), p. 7 and (1990), p. XXIII.

${ }^{38}$ Cf. Giusti (1990), pp. XIII-XLVII.

${ }^{39}$ Cf. Giusti (1981), p. 19 et (1990), pp. XXIX-XXX.
} 
While Galileo bases his "new science" on the theory of proportion, Newton" 40 has completely absorbed the new Cartesian geometry. What was essentially new in Cartesian geometry ${ }^{41}$ was the definition of internal product and ratio between two continuous quantities: according to such a definition two continuous quantities could be multiplied and divided one for the other, the result being a third continuous quantity. This quantity is not understood by Descartes as produced by multiplication or division but it is only selected as the result of these operations in a domain of existing quantities, according to the previous choice of a unity. If the multiplied or divided quantities are homogenous and the chosen unity is also homogenous to them, the resulting quantity is necessarily homogenous to its factors. This is the case implicitly considered by Descartes in his definitions. Since these definitions use classical proportions, and a proportion does not require the homogeneity of the four quantities occurring in it, such a complete homogeneity is not necessary, however.

Let be $u$ the unity and $a, b$ and $c$ three continuos quantities such that $a: c=u: b$. If $a$ and $b$ are given and they are homogenous with each other, $u$ must also be homogenous with $a$ and $b$ and the Cartesian product $c$ of $a$ and $b$ is necessarily homogenous with its factors. However, if $a$ and $b$ are given and they are not homogenous with each other, such a proportion requires only the homogeneity of $u$ with $b$ and of $c$ with $a$. Because of the commutativity of multiplication, this means that the Cartesian product of two non homogeneous quantities $a$ and $b$ can be homogenous either with $a$ or with $b$.

Let us imagine now that $c$ and $b$ are given and they are not homogeneous. The Cartesian ratio $a$ of $c$ and $b$ is necessarily homogenous with $c$. But $a$ can be also intended as the ratio of two other (homogenous) quantities $C$ and $B$ that are both not homogenous with it, and thus with $c$, and this ratio can be, at its turn, intended as equal to a new quantity $A$ non homogeneous both with $c$ and $b$. The Cartesian ratio of the two non homogeneous quantities $c$ and $b$ can then be equal to a quantity $A$ non homogeneous with both $c$ and $b$. Thus-even without introducing measures of these quantities by means of segments or any other

\footnotetext{
40 Newton mathematical theory of motion is exposed in the two first books to the Principia [cf. Newton (1687)].

${ }^{41}$ Cf. Descartes (1637), pp. 297-298 and, for a commentary on this point, Bos and Reich (1990), pp. 199205 and Jullien (1996), pp. 75-76.
} 
elements of a universal class of quantities ${ }^{42}-$ it is possible to imagine, in the Cartesian framework, that speed is the ratio of space and time and that it is not homogeneous with both the former and the latter. The same is true of acceleration, that is now the ratio of speed and time, even though it is not, as such, homogeneous with both speed and time.

This is a very nice situation from the point of view of definitions, but it is quite impossible to imagine how these definitions could be translated as such in the principles of a mathematical science of motion. The difficulty is obvious: Cartesian definitions of algebraic operations on continuous quantities are not, as such, constructive; they provide the conditions under which a certain quantity is the product or the ratio of two other given quantities, but they do not provide, as such, this product or ratio, even though the unities are fixed. Thus, they do not provide as such any way to compare, respectively, two different speeds or two different accelerations with each other.

It is to solve such a difficulty (and not to provide suitable definitions) that Newton has to assume the reducibility of any mechanical quantity to its "measure" in terms of the elements of the universal class of segments. Segments are, in fact, the only continuous quantities for which Descartes provided not only a definition of internal multiplication and ratio but also showed how the results of these operations (as well as of power and of any sort of integral root) could de constructed. This means that if a certain motion is given, by giving the measures, in terms of segments, both of the space it covers and of the time taken to do it, then the measures of its speed and acceleration can be easily constructed under the form of suitable segments. It is just this construction that provides both a sense for algebraic (or even numerical) calculation of these quantities, and makes their algebraic expressions able to denote a proper object ${ }^{43}$.

But a new difficulty arises. If the space covered by any motion is represented by a segment, Cartesian geometry cannot be used for representing trajectory of non rectilinear motions. Newton's central idea to solve such a difficulty is directly connected to the Newtonian conceptions of inertia and force, since it appeals to the composition of motion.

\footnotetext{
42 Cf. Giusti (1993), p. 169.

${ }^{43}$ For a precise characterization of the notion of proper object, cf. Panza (1997b).
} 
The motion of any sort of body is represented by the curve described by a point reacting in a specific way to certain forces in the three-dimensional space where the motion takes place. If no force acts upon a moving body, it moves of a rectilinear uniform motion; other sorts of motions are due to the action of forces that accelerate the body and change its direction. The rectilinear direction of original uniform motion combines itself with the rectilinear directions associated with any force acting on it. If a force acts punctually upon the body, it changes its direction and speed, but as the force acts only in one point, after this point the body moves of a uniform rectilinear motion, as long as no other force occurs. Curvilinear trajectories are thus only possible if one or more forces act continuously upon the body and change continuously its direction. A single non rectilinear motion is then understood as a continuous composition of continuous changing virtual and rectilinear motions. Thus, at any point of the curvilinear trajectory of this motion, distinct virtual motions are associated, expressing the punctual speed of this motion and the forces acting in this point upon the moving body. Even though speed and forces are variable, these punctual virtual motions are not only rectilinear, but also uniform, since they express a punctual value of speed and forces. Hence, they are represented by suitable segments: the former by an oriented segment taken on the tangent to the curve (since the direction of this tangent is just the punctual direction of the curve), with its origins in it; the latter by any oriented segment with the same origin. Of course, two constant speeds or forces $\varphi$ and $\psi$ (or the punctual values $\varphi$ and $\psi$ of two speeds or forces) have to be respectively represented by two segments $A$ and $B$ verifying the proportion $\varphi: \psi=A: B$. In general, Newton interprets these segments as a representation of the rectilinear spaces that would be covered in a certain time by a body moving according to the rectilinear uniform motion expressing these speeds or forces (or their punctual values). Under this interpretation, they are measures of speeds and forces, since they represent spaces that measure motions, expressing speeds and forces. As long as speeds and forces are measured by these segments, they compose each other according to the law of the parallelogram applied to them. Finally, speeds and forces are related by the condition of proportionality between force and acceleration (where the constant of proportionality is intended as the mass of the moving body and it is consequently the same for any force acting upon the same body).

Newton mechanics develops, according to these premises, as a geometry of trajectoriesreferred to two or three Cartesian coordinates and described by points with a constant 
mass - to each position of which suitable vectors representing punctual speeds and forces are associated. Time is in general understood as an external common parameter, fixing the measure of uniformity for the variation of any considered quantity. The aim is to determine trajectories, if forces and initial speeds and positions are given, or forces, if trajectories and initial speed and positions are given ${ }^{44}$. If only one body is considered, its mass can be taken as unitary. But it is also possible that the motions of two or more bodies are connected with each other, either because the moving bodies are linked, or because the forces acting upon each of these bodies depend on the masses and positions of the other bodies. If it is the case, we are faced with a an $n$-bodies problem.

Since motions are considered as the effects of forces (or inertia), Newton mechanics is, as Aristotelian science of motion, a dynamic, rather than a kinematics. Nevertheless, as long as speeds and forces are no more understood by Newton as constant or variable qualities of motion, the latter is nothing else but a mathematical object. Thus, as long as it is studied by means of the mathematical theory introduced by Newton, motion is not given as a real external phenomenon. Rather, it is given as a mathematical object, once a certain system of connected geometrical entities is given. Hence, the Newtonian theory of motion is not only a mathematical science, i.e. the result of the application of mathematics to the study of motion, but it is also a science of mathematical objects, , i.e. the result of a process of mathematisation. Mathematics is not just a tool which is able to provide suitable characterizations of natural phenomena, as it was for Galileo; rather it is now a science inside which suitable models for natural phenomena are constructed and studied.

As long as motion is, for Newton, a mathematical object, it is essentially a geometrical one. It is a relation between two magnitudes, represented by a certain curve, which has to be studied by a new sort of geometry. One of the aims of analytical mechanics in 18th century is that of transforming the Newtonian science of motion in an analytical science, i.e. to pass from a geometrisation of the science of motion to a new theory of motion where the latter is just an analytical object. I shall try to describe briefly this transition in the next paragraph.

\footnotetext{
44 On the mathematical methods of Newton's mechanics, cf., among many other works, Herivel (1965) Whiteside (1966) et (1970), Cohen (1971), De Gandt (1986) and (1995), RVS (1987), Barthélémy (1992). In my (1991a), I have discussed an example of Newton treatment of motion of an isolated body, by comparing it to Lagrange's solution to the same problem.
} 


\section{Analytical Mechanics}

As long as speed is defined in general as a ratio between a certain space and a certain time, it could seem very natural to express punctual speed as the differential ratio $d s / d t$ and consequently punctual acceleration by $d v / d t=d^{2} s / d t^{2}$. However, in order to understand these ratios as proper objects, that is quantities which could be exhibited, post-Cartesian mathematicians had to interpret them as the ratios of two segments, measuring respectively differentials or fluxions of space and time. Of course, they could assign a numerical value to them, but as long as continuity were not considered as a property of the field of real numbers (like in the modern conception based on Cantor-Dedekind's construction), this value can only be understood as a numerical expression of a continuous quantity, like a segment ${ }^{45}$. Thus, an analytical expression of mechanical quantities in terms of differentials or could not be understood in the end of 17th century as independent from a geometrical interpretation of them. Moreover, since the essential law of composition of motions (that provided also compositions of forces) was intrinsically geometrical ${ }^{46}$, as well the Newtonian representation of trajectories of motions as curves referred to two or three Cartesian coordinates, no analytical formulation of the new science of motion in terms of differential calculus could be independent from a geometrical basic treatment. Namely, such an analytical formulation could not be anything else than an analytical description of a geometrical model. Even though such a description would have simplified many Newtonian proofs, by using algebraic formalism where these proofs advanced by considering geometrical relations, it is a matter of fact that Newton never appeals to it. A number of reasons have been advanced to justify such an apparently strange attitude. However, I take it that one of them is that such a treatment would be probably appeared to Newton as an

\footnotetext{
45 Before Cantor defined a real number as the limit of a Cauchy's succession of rational numbers, no justification was possible for the practice of using numbers in order to expresse continuous quantities. In such a situation, to ascribe to a segment (or any other continuous quantity) a numerical value was only a practical simplification without any justification.

${ }^{46}$ On the law of composition of motion and forces in the XVIIIth century, cf. Dhombres (1986), Dhombres et Radelet De Grave (1991) and Radelet De Grave (1987), (1988) et (1989).
} 
unnecessary translation of an intrinsically geometrical science (where simplicity could have been gained at the expense of a loss of rigor, globality and intelligibility).

As I have already said, the mathematical object of the Newtonian science of motion (that is just motion as a mathematical object) was intrinsically a geometrical object. With the term "intrinsically" I mean that this geometrical nature did not depend merely on an expository choice of Newton, but it depended on Newton's conceptualisation of the objects of his science.

Nevertheless, once Newton's Principia had been studied and understood, an analytical formulation of its principal definitions, results and proofs in terms of differential calculus, should have not been quite easy to obtain for a good mathematician of the end of 17 th century. As I have already said, the first programmatic effort in this direction was made by Varignon. According to Blay's reconstruction, this effort could be considered as the third stage of a progressive process along which - in the years following the publication of the $N^{`}$ va Meth $d u s^{47}$-Leibnitian calculus appropriates the theory of motion.

The first stage of this process ${ }^{48}$ is marked by a number of differential solutions for problems concerned with the determination of a certain curve responding to certain cinematic or dynamic properties, like the isochrone, the brachistochrone or the curve of equal pressure. What is typical of these solutions (proposed for the most part by Leibniz and Jacob and Johann Bernoulli) is that they proceed all from a preliminary reduction of the problem to a purely geometric condition, and apply then the differential calculus to such a condition. Thus, as Blay remarks, they "ne present finallement aucune conceptualisation différentielle spécifique de la science du mouvement"49. Moreover, the preliminary reduction does not depend on any geometrical representation (by means of the Newtonian vectors or anything else) of speed or forces, being founded on known relations between these latter entities and certain entities entering the usual geometrical representation of the searched trajectory.

\footnotetext{
${ }^{47}$ Cf. Leibniz (1684).

${ }^{48}$ Cf. Blay (1992), part. I, ch. 3, pp. 63-109, where the necessary bibliographical references are given.

${ }^{49}$ Cf. ibid., p. 109.
} 
The second stage ${ }^{50}$ is completely due to Leibniz and consists in the establishment of a differential expression for the relations occurring in any motion between the instantaneous speed and both the elements of space and time and the elements of this speed itself. Leibniz reaches, for example, the determination of a "general principle", where he generalises the law asserting that the speeds of two uniform motions are between them in the composed ratio of the ratio of distances and the inverse ratio of times, by stating a relation of proportionality between $d s$ and $v d t^{51}$. As Blay remarks, this not yet a differential characterisation of the instantaneous speed. Rather, instantaneous speed is geometrically represented by certain (infinitesimal) segments, that are thought as rectilinear spaces covered in a given time, in such a way that it is impossible to calculate the times when spaces and speeds are given ${ }^{52}$.

Finally, the third stage ${ }^{53}$ consists in Varignon's differential characterisation of the principal notions of Newton's theory and of their general relations. This is done by means of a geometrical representation not only of certain linear spaces or trajectories, but also of times speeds and accelerative forces. This representation enables Varignon to eliminate any constraint of homogeneity, since it allows him to compare spaces, times, speeds and accelerative forces by means of a comparison of segments and leads him to the crucial identities $v=\frac{d s}{d t}, d v=\frac{d^{2} s}{d t}$ and $\gamma=\frac{d v}{d t}$ ( $\gamma$ being the accelerative force). These identities make the solution of a number of cinematic and dynamic problems independent of a geometric analysis: if the data are expressed by means of suitable equations, the solutions can also be expressed by other equations derived by using the algorithm of the calculus. As Blay says:

[Varignon] elabore la solution de[...][ces] problèmes, non plus comme ses prédécesseurs, à partir des éléments géométriques représentés dans telle ou telle figure, mais directement à partir des relations entre les symboles. Dans cette perspective [...], la figure, essentielle pour le développement et l'organisation de la pensée géométrico-infinitésimale, devient progressivement avec Varignon simple

\footnotetext{
${ }^{50} \mathrm{Cf}$. ibid, part. II, ch. 1, pp. 113-152, where the necessary bibliographical references are given.

51 Cf. ibid., p. 129.

52 Cf. ibid., pp. 150 and 152.

${ }^{53}$ Cf. ibid, part II, ch. 2, pp. 153-221, where the necessary bibliographical references are given.
} 
diagramme. C'est-à-dire que cette figue perd sa valeur traditionnelle d'intellection pour prendre une valeur toute secondaire d'illustration ${ }^{54}$.

Varignon's approach was largely improved by the treatment of mechanical problems in the Leibnitian school, in particular by Jean Bernoulli55, and is the basis both of Euler's Mechanica $^{56}$ and of the footnotes of Le Seur and Jacquier to Geneva's edition of the Principia ${ }^{57}$, where a number of Newton's proofs and arguments are reformulated in analytical terms, according to the algorithm of the calculus.

As I have already said, there is certainly a sense according to which these important results constitute the first stage of analytical mechanics, they mark the birth of it, as Blay says. However, there is also a sense according to which the birth of analytical mechanics is not there, it does not only depend only on the translation of Newton's definitions, principles and proofs in the analytical language of differential (or fluxional) calculus.

A first remark is obvious: all the differentials entering Varignon's formulation of mechanical relations are infinitesimal differences between segments or portions of curves; moreover, they measure (or express) mechanical entities, just because they are infinitesimal differences. As long we deal with a cinematic or a simple dynamic problem, this is nothing but a question of interpretation of algorithmic procedures, but when a more difficult problem is considered the geometrical nature of Varignon's approach becomes manifest from an operative point of view too.

Let us consider the example of the expression of the punctual central force that is responsible for a curvilinear motion ${ }^{58}$. The following is a simplified version of Varignon's argument drawn from Blay's reconstruction ${ }^{59}$. Let QL be the trajectory described by a moving body because of a central force with centre in $\mathrm{C}$. Let $\mathrm{AH}=x$ and $\mathrm{HL}=y$ be the coordinates (respectively linear and circular, with centre in $\mathrm{C}$ ) of the running point $\mathrm{L}$.

\footnotetext{
${ }^{54}$ Cf. ibid., p. 161.

55 Consider, for example, the famous controversy on the inverse problem of central forces on which cf. Bertoloni-Meli (1993), pp. 208-215, where a bibliography is given.

$56 \mathrm{Cf}$. the pervious footnote (10).

57 Cf. Newton (G).

58 It is the object of Varignon (1700) on which cf. Blay (1992), pp. 193-213.

${ }^{59}$ Cf. Varignon (1700), p. 85 and Blay (1992), pp. 197-198.
} 
Varignon considers a point $l$ infinitesimally close to $\mathrm{L}$ and assumes that the accelerative force $\gamma$ acting on L during the time $d t$ is proportional to the infinitesimal segment LR. Then, he decomposes this forces into two orthogonal components taken respectively on the direction of the tangent LM and the normal LN to QL in L. Since $\gamma$ and its orthogonal components can be taken as constant during $d t$, we can assume the identity $\frac{\gamma_{t}}{\gamma}=\frac{\mathrm{LP}}{\mathrm{LR}}$, where $\gamma_{t}$ is the tangential component of $\gamma$. Now, because $L$ and $l$ are two points infinitely close to each other, the infinitesimal curvilinear triangle $\mathrm{LR} l$, can be considered as a rectilinear one, which is similar to the infinitesimal triangle LRP. Hence, we will have also $\frac{\mathrm{LP}}{\mathrm{LR}}=\frac{\mathrm{LR}}{\mathrm{L} l}$ and thus: $\frac{\gamma_{t}}{\gamma}=\frac{d x}{d s}$ or $\gamma_{t}=\gamma \frac{d x}{d s}$. Consider now the (virtual) rectilinear motion along LM, due to the force $\gamma_{t}$. Since this motion is rectilinear, it satisfies the identities $d^{2} s=d v d t$ and $d v=\gamma_{t} d t$, which entail: $d^{2} s=\gamma \frac{d x}{d s} d t^{2}$ or $\gamma=\frac{d s d^{2} s}{d x d t^{2}}=v \frac{d v}{d x}$.

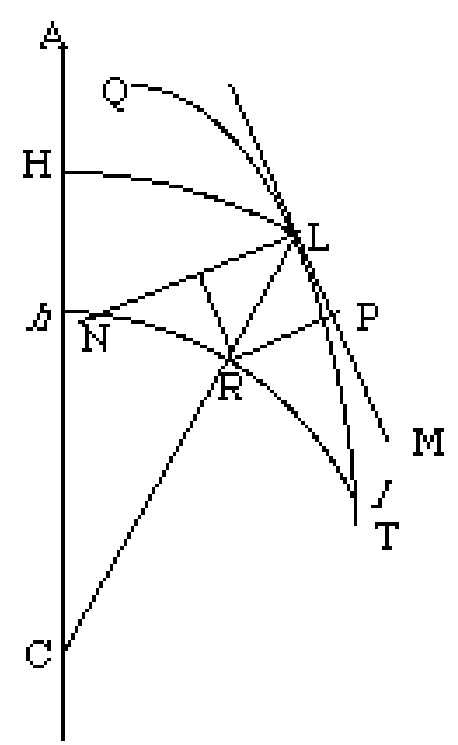

Even though it uses the differential algorithm, this argument consists of a Newtonian analysis of the central force acting upon the body. This is a very simple exemplification of my point: Varignon's differential expression of mechanical quantities and relations does not enable him (when the problem is a dynamic one and non rectilinear motions are concerned) to avoid any appeal to the Newtonian method of analysis of forces, which is founded on the consideration of intrinsically geometrical models. Now, according to the meaning of this 
term I am considering here, what is essential in order to speaking about "analytical mechanics" is neither the expression of speed and acceleration by means of differential or fluxional ratios, nor the expression of the link between the different variables occurring in a geometrical model of motion by means of suitable equations where analytical forms occur. Rather, it is just the substitution of Newtonian geometrical models with equations of motion as a basic description of a certain mechanical situation. When simple situations are considered, the difference between these two approaches is not always evident and often vanishes. In a sense, Newton himself uses his principles to determine equations of motions (even though these equations are always understood as a description of a geometrical model), and the basic idea of determining standard forms for equations expressing the data of a mechanical problem of a certain sort and containing its solution is already explicit in Varignon's memoirs-particularly when resisting motion is considered ${ }^{60}$ - Bernoulli's solution of the problem of shock of bodies ${ }^{61}$ and, overall, Euler's Mechanica. Nevertheless, in all these texts, equations of motions are the result of an analysis of forces - a real Pappusian analysis, applied to geometrical models of mechanical problems - and their general form results from codified methods for such an analysis, which are applied to different sorts of problems.

In the original sense of such a term - that Viète and Descartes had inherited by Pappus this is a very analytical procedure, since it starts with the assumption of what is searched as it were given ${ }^{62}$. But it is not so, if the term is taken in the new sense it will take in 18th century. In 18th century, mathematical analysis is neither the first stage of the Pappusian "method of analysis and synthesis", nor a particular procedure for solving mathematical problems - as it is in classical language. Moreover, it is not a branch of mathematics - as it is today . It is a mathematical theory - the new theory of functions - but it is not a particular theory among many other, since its aim is a reformulation of mathematics as a whole: a function is not a particular mathematical object, among a number of other mathematical objects, rather it is an abstract representation of a quantity, and mathematics is just the

\footnotetext{
60 Cf. in particular Varignon (1707) and for a commentary Blay (1992), pp. 280-299 and Panza (1991a), pp. 523-524.

61 Cf. Bernoulli (1727).

${ }^{62}$ Cf. on this point Otte and Panza (1997) and in particular Panza (1997a).
} 
science of quantities ${ }^{63}$. Considered as functions, quantities need not to be distinguished between numbers (or discrete quantities) and magnitudes (or continuous quantities), and magnitudes need not to be qualified, according to their specific nature. As long as it is represented by a certain function, a quantity need not to be exhibited as such, and it is not necessary to give specific criteria of identity for it. General criteria for functions work in any circumstance and if we are studying a particular sort of quantities, we must only provide a suitable interpretation of a consistent formalism. Thus, 18th century mathematical analysis is a unitary formulation of mathematics. In fact; it is the first unitary exposition of the science of quantities. More generally, in 18th century science and philosophy, the ideal of analysis is that of a logic organisation of knowledge, according to an internal and unitary order coming from general principles or elements ${ }^{64}$, and transmitting to particular applications of them. The place of mechanics, in such an organisation, is not simply that of a collection of standard methods for solving problems concerning with motion, or, as Truesdell says, with "the enforced changes of positions and shape which [...] things suffer" 65 . Rather, it is the place of the science of these changes, understood as general and universal phenomena expressed by mathematical objects and governed by general laws of nature.

In such a framework, the program of analytic mechanics could not have been merely a program of exposition of Newtonian mechanics by means of a certain language. It was a program of edification of a more general science, founded on general principles expressing the natural laws of motions (rather than on Pappusian analysis of geometrical models), where Newton's results are particular cases of general results. Of course, the general theory of functions could not provide, as such, the principles of this science. However, these principles were expressed by general equations where suitable functions occur, in such a way that mathematical deduction could operate starting from them according to the methods and results of the general science of functions (that is analysis) in order to provide the particular equations characterising a particular mechanical situation.

\footnotetext{
63 I have discussed this topic at length in Panza (1992), Ch. II.2.

${ }^{64}$ Cf. d'Alembert (El. Sci.).

${ }^{65} \mathrm{Cf}$. the previous footnote (5).
} 
Let us consider the example of the problem of motion of one or more bodies again. The essential aim of what I would like to call "analytical mechanics", as long as it was concerned with this problem, was to determine a little number of general principles-like those of the least action, the conservation of the vis viva or the virtual velocities - according to which it were possible to express the dynamic characters of a system of $n$ bodies, upon which any sort of forces act, by means of suitable equations ${ }^{66}$. As long as these equations were general, they referred to any sort of mechanical system, independently from the number of bodies and forces acting on them. Strict sensu, they were forms or schemes of equations. But, as long as forms or schemes of equations are equations, they worked, at the same time, as the starting point of deductive proofs of general results relative to any sort of mechanical system, and as the guidelines for writing the equations of motion of particular systems. From such a point of view, motion is no longer merely a mathematical object, rather, it is an analytic object, i.e. a functional relation expressed by an analytical form.

This approach was not only different from the Newtonian one for epistemological reasons. It made also possible address problems that no analysis of force could solve, as those concerning a great number of bodies. Moreover, from such a point of view, the different systems of bodies became elements of an infinite domain of objects of a common and universal form that could be easily expressed in general. As Kant said, it made possible to treat motion as a "universal in c'ncret" "67.

Understood in this way, i.e. as a system of deductive consequences of general principles expressed by suitable equations (or forms of equations), 18th century analytical mechanics seems to be completely independent of Newtonian geometrical models and analysis of forces.

However, this is not the case, if the question of justification of the general principles is considered. In fact, even though these principles were often formulated in metaphysical terms and supported by metaphysical arguments, they could only be translated in a certain equation when they were applied to something such as a simple, and easily generalisable, mechanical model, which is, necessarily, in 18th century, a Newtonian geometrical model. This is even clearer if mathematical arguments are considered. These arguments were either

\footnotetext{
66 Cf. on this point Panza (1991b), (1996a) and (1999)

${ }^{67}$ Cf. Kant (A), pp. 734-735, and (B), pp. 762-763.
} 
a pri ${ }^{\prime} i$ or $a p^{`}$ steri $^{`}{ }^{6}{ }^{68}$. The former tried to deduce the equations expressing the general principles directly from something as a Newtonian analysis of forces applied to a general system; the latter merely consisted in the verification of the equivalence between the consequences of the general principles when they were applied to simple systems and the consequences of Newtonian analysis of force applied to the same systems. In the same way, and for obvious reasons, 18th century mechanics could not be independent of Newtonian geometrical models, if the aim was to give a proper mechanical content both to the analytical description of a mechanical situation and to the different sorts of mechanical equations.

Thus, an unsolved tension, between the philosophical need of elimination of Newtonian geometric analysis of forces and the mathematical need of appealing to them is intrinsic in the birth and evolution of analytical mechanics in 18th century: in my sense, no history of this birth and evolution is possible if it is not also a history of such a tension, which is also a tension between two distinct way of accomplishing a mathematisation of the science of motion.

\section{Bibliographical References}

\section{Alembert, J. B. I. R. d'}

(El. Sci.) "Elémens des sciences" (1st part), in Encycl pédie, `u dicti`nnaire rais`nné des sciences, des arts et de métiers, Briasson, David l'aîné, le Breton, Durand, Paris, 1751-1780 (35 vols.), vol. V, 1755, pp. 491a$497 \mathrm{a}$.

\section{Aristotle}

Physics $\Phi v \sigma \iota \kappa \tilde{\eta} \varsigma \alpha \dot{\alpha} \kappa \rho o \alpha \sigma \varepsilon \omega \varsigma$, in Arit teles graece, ex recensione I. Bekkeri, editit Academia Regia Borusica, apud G. Reinerium, Berolini, 1831 (2 vols.), vol. I, pp. 184-267.

\section{Barthélémy, G.}

(1992) Newt`n Mécanicien du c`sm`s, Vrin, Paris, 1992.

\section{Bernoulli, Jean}

(1727) Disc`urs sur les l`ix de la c`mmunicati`n du m`uvement [...], C. Jombert, Paris, 1727.

\footnotetext{
${ }^{68}$ On the distinction among these three sorts of arguments in justifications of the principles of analytical mechanics, cf. my (1996a), par. 1 .
} 


\section{Bertoloni-Meli, D.}

(1993) Equivalence and Pri` rity: Newt` $n$ versus Leibniz, Clarendon Press, Oxfoed, 1993.

Blay, M.

(1992) La naissance de la mechanique analytique. La science du m`uvement au t’urnat des XVIIème et XVIIIème siècle, PUF, Paris. 1992.

Bos, N. H. and Reich, K.

(1990) "Der Doppelte Auftakt zur frühneuzeitlichen Algebra: Viète und Descartes", in E. Scholz (ed. by), Geschichte der Algebra, Wissenschaftverlag, Mannheim, Wien, Zürich, 1990, pp. 183-234.

\section{Carteron, $\mathbf{H}$.}

(1923) La n`ti`n de f`rce dans le systhéme d'Arist` tle, Vrin, Paris, 1923.

\section{Clagett, $M$.}

(1959) The Science `f Mechanics in the Middle Ages, Univ. of Wisconsin Press, Madison (Wisconsin) 1959.

(1968) Nic`las Oresme and the Medieval Ge`metry `f Qualities and M`ti` $n$. A Treatise `n the Unif rmity and Diff rmity `f Intensities Kn`wn as Tractatus de c`nfigurati`nibus qualitatum et $m$ ` tum (Edited with an Introduction, English Transaltion and Commentary by M. Clagett), The Univ. of Wisconsin Press, Madison, Milwaukee, London 1968.

\section{Cohen, I. B.}

(1971) Intr`ducti`nt`Newt`n's Principia, Harverd Univ. Press, Cambridge (Mass.), 1971.

\section{Dhombres, J.}

(1986) "Un styl axiomatique dans l'écriture de la physique mathématique au 18ème siècle. Daniel Bernoulli et la composition des forces", Sciences et Techniques en Perspective, 11, 1986-1987, pp. 1-38.

\section{Dhombres, J. et Radelet De Grave, P.}

(1991) "Cntingence et necessité en mecanique. Etude de deux textes inedits de Jean d'Alembert", Physis, 28, 1991, pp.35-114.

\section{Descartes, $\mathbf{R}$.}

(1637) La Gê métrie, in R. Descartes, Disc`urs de la Méth de [...]. Plus la Di`ptrique. Les Mété res. Et la Gé métrie qui s`nt des essaies de cette Méth`de, I. Maire, Leyde, 1637, pp. 295-413.

\section{De Gandt, F.}

(1986) "Le style mathématique des Principis de Newton", Revue d'Hist`ire des Sciences, 39, 1987.

(1995) F`rce and Ge`metry in Newt`ns's Principia, Princeton Univ. Press, Princeton, 1995.

\section{Euler, L.}

(1736) Mechanica, sive m`tus scientia analytice exp`sita, ex typ. Acad. sci. imp., Petropoli, 1736 (2 vols.). 
(1750) "Découverte d'un nouveau principe de mécanique", Méem. Acad. Sci. Berlin, 6, 1750 (publ. 1752), pp. 185-217.

\section{Fraser, C.}

(1994) “Classical mechanics”, in I. Grattan-Guinness (ed. by), C`mpani` $n$ Encycl pedia ` $f$ the Hist` ry and Phil`s`phy 'f the Mathematical Sciences, Routledge, London and New York, 1994 (2 vols. with continued pagination), pp. 971-986.

\section{Galilei, G.}

(1632) Dial g` [...] s`pra i due Massimi Sitemi del M`nd` [...], G. B. Landini, Fiorenza, 1632 [in G. Galilei, Le Opere, Ed. Nat., a cura di A. Favaro, Barbera, Firenze, 1890-1909 (20 voll.), vol. VII].

(1638) Disc`rsi e dimstrazi ni matematiche int 'rn`a due nu`ve scienze..., Appresso gli Esevirii, Leida, 1638 [in G. Galilei, Le Opere, cit., vol. VIII].

\section{Giusti, E.}

(1981) "Aspetti matematici della cinematica galileiana", $B^{`}$ 'llettin` di st’ ria delle scienze matematiche, $\mathbf{1}$, 1981, 2, pp. 3-42.

(1990) "Galilei e le leggi del moto", in G. Galilei, Disc`rsi e dim`strazi`ni matematiche int `rn`a due nu`ve scienze..., ed. by E. Giusti, Einaudi, Torino, 1990, pp. IX-LX.

(1993) Euclides ref rmatus. La te`ria delle pr`p`rzi`ni nella scu`la galileiana, Bollati Boringhieri, Torino, 1993.

\section{Herivel, J. W.}

(1965) The Backgr`und `f Newt`n's Principia. A Study `d Newt`n's Dynamical Researches in the Years 1664-1684, Clarendon Press, Oxford, 1965.

\section{Jullien, $\mathbf{V}$.}

(1996) Descartes. La Géométrie de 1637, PUF, Paris, 1996.

\section{Kant, I.}

(A) Kritik der reinen Vernunft, Hartknoch, Riga, 1781; the pages 1-405 are in Kant's gesammelte Schriften (herausg. von de Königlich Preukischen Akademie der Wissenschaften; after: Deutsche Academie der Wissenschaften zu Berlin. after: Academie der Wissenschaften der D.D.R.), G. Reimer and (from 1922) W. De. Gruyter, Berlin, 1900-..., vol. IV, 1911, pp. 1-252.

(B) Kritik der reinen Vernunft, Hartknoch, Riga, 1787; ibid., vol. III, 1911, pp. 1-552.

\section{Lagrange, J. L.}

(1788) Méchanique analitique, La veuve Desaint, Paris 1788; IInd ed., Mecanique analytique, Courcier, Paris, 1811-1815 (2 vols.). 


\section{Leibniz, G. W:}

(1684) "Nova methodus pro maximis et minimis [...]”, Acta Erudit rum, 1684, pp. 467-473.

\section{Newton, I.}

(1687) Phil`s`phice naturalis principia. mathematiaca [...], Jussu Soc. Regiæ ac Typis J. Streatner, Londini 1687; 2h. ed., without publisher, Catabrigiæ, 1713; 3th ed., apud G. and J. Innys, Londini, 1726].

(G) Phil`s phice naturalis principia. mathematiaca, perpetuis Commentariis illustata, communi studio PP. T. Le Seur \& F. Jacquier, Barrillot \& Filli, 1739-1742 (3 toms in 4 vols.).

\section{Otte, M. and Panza, M.}

(1997) (ed, by) Analysis and Synthesis in Mathemetics. Hist`ry and Phils`phy, Boston Studies in the Philosophy of Science, 196, Kluwer, Dordrech, Boston, London, 1997.

\section{Panza, M.}

(1991a) "Eliminare il tempo: Newton, Lagrange e il problema inverso del moto resistente", in M. Galuzzi (ed. by), Gi` rnate di st` ria della matematica (proceedings of the meeting held in de Cetraro, September, 8th12th 1988), Editel, Commenda di Rende (Cosenza), 1991, pp. 487-537.

(1991b) "The Analytic Foundation of Mechanics of Discrete Systems in Lagrange's Thê rie des F`ncti'ns Analytiques, Compared with Lagrange's Earlier Treatements of This Topic", Hist' ria Scientiarum, 44, 1991, pp. 87-132 and 45, 1992, pp. 181-212.

(1992) La f rma della quantita. Analisi algebrica e analisi superi re: il pr`blema dell'unità della matemetica nel sec`l` dell'Illuminism `, Cahiers d'Hist`ire et de Phil`s phie des Sciences, 38 and 39, 1992.

(1994) "Dalla metafisica del moto alla scienza matematica della natura. Considerazioni critiche a proposito di alcuni problemi cinematici trecenteschi", in L. Bianchi (ed. by), Fil`s`fia e te`l'gia nel trecent `. Studi in ric` $r d `$ di Eugeni`Randi, édité par la Fédération Internationale des Instituts d'Etudes Médiévales, Louvain la Neuve, 1994, pp. 413-478..

(1996a) "De la nature épargante aux forces généreuses : le principe de moindre action entre mathématiques et métaphysique. Maupertuis et Euler, 1740, 1751", Revue d'hist`ire des Sciences, 48, pp. 435-520.

(1997a) "Classical sources for the concepts of analysis and synthesis", in Otte and Panza (1997), pp. 365414.

(1997b) "Quelques distinctions à l'usage de l'historiographie des mathématiques", in J.-M. Salanskis, F. Rastier, R. Sceps (éd.), Herméneutique: textes, sciences, P.U.F., Paris, 1997, pp. 357-383.

(1999) “Die Entstehung der analytischen Mechanik im 18. Jahrhundert”, in H. N. Jahnke (Hrsg.), Geschichte der Analysis, Spektrum Akad. Verl., Heidelberg, Berlin, 1999, pp. 171-190. 


\section{Radelet De Grave, $P$.}

(1987) "Daniel Bernoulli et le parallélogramme des forces", Sciences et Techniques en Perspective, 11, 1987, pp. 1-20.

*(1988) "Les forces et leur loi de composition chez Newton", Revue Philosophique de Louvain, 86, 1988, p. $505-522$.

(1989) "La composition des mouvements, des vitesses et des forces", in H.-J. Hesse und F. Nagel (hrsg. von), Der Ausbau des Calculus durch Leibniz und die Brüder Bernoulli [...], Studia Leibnitiana, Sonderheft 17, 1989, pp. 25-47.

\section{RVS}

(1987) Les Principia de Newton. Question et commentaires, special issue of the Revue d'histoire des sciences, 40, 3/4, 1987.

\section{Truesdell, $\mathbf{C}$.}

(1968) Essays in the History of Mechanics, Springer-Verlag, Berlin, Heidelberg, New York, 1968.

(1977) A First Course in Rational Continuum Mechanics, vol. 1, Academic Press, New York, San Francisco, London, 1977.

\section{Varignon, $\mathbf{P}$.}

(1700) "Du mouvement en général partout sorte de courbes, et des forces centrales, tant centrifuge que centripètes, nécessaires aux corp qui les décrivent”, Hist. Acad. Roy. Sci. [de Paris], Mém. Math. Phy., 1700 [publ. 1703; pres. 31/3/1700], pp. 83-101.

(1707) "Des mouvements faits das des milieux qui leur résistent en raison quelconque", Hist. Acad. Roy. Sci. [de Paris], Mém. Math. Phy., 1707 [publ. 1708; pres. 13-17/8/1707], pp. 382-476.

(1725) Nouvelle mécanique ou statique, C. Jombert, Paris 1725 (2 vols).

\section{Verlet, $\mathbf{L}$.}

(1996) " $F=m a$ and the Newtonian Revolution: an Exit from Religion through Religion", History of Science, 34, 1996, pp. 303-346.

\section{Whiteside, D. T.}

(1966) "Newtonian Dynamics", History of Sciences, 5, 1966

(1970) "The Mathematical Principles underling Newton's Principia Mathematica", Journal for the History of Astronomy, 1, 1970, pp. 116-138. 